\title{
Predictors of Team Work Satisfaction
}

\author{
James H. Hamlyn-Harris, Barbara J. Hurst, \\ Karola von Baggo, Anthony J. Bayley \\ Faculty of Information and Communications Technology, \\ Swinburne University of Technology, Melbourne, Australia
}

\author{
jhamlynharris@swin.edu.au bhurst@swin.edu.au \\ kvonbaggo@it.swin.edu.au abayley@swin.edu.au
}

\section{Executive Summary}

The ability to work in teams is an attribute highly valued by employers of information technology (IT) graduates. For IT students to effectively engage in team work tasks, the process of working in teams should be satisfying for the students. This work explored whether university students who were involved in compulsory team work were satisfied with their experience. The research was seeking predictors of satisfaction with team work which may lead to educators being able to plan interventions that improve students' experiences. Team work satisfaction was measured by asking students to reflect on their current team work experience while rating their level of agreement with statements relating to Global Satisfaction (e.g., Group members interact well with each other.) and Global Dissatisfaction (e.g., My group isn't very efficient). The statements were taken from a set generated by Keyton (1991) in her study of group work satisfaction in university level students. Potential predictors were also assessed by the survey and included: previous experience with team work; perceived usefulness of team work training; familiarity with team members; and gender mix within the team.

Two cohorts of students were surveyed. The first consisted of 270 Database 1 (DB1) students working in teams of 3-4 students on a short duration project (5 weeks). Most of these students were at the beginning of their degrees and therefore relatively inexperienced in regards to team work. The second contained 100 Software Engineering Project (SEP) students who were in the final stages of their degree. These students had more experience with team work than the Database students, and were working on a longer project ( 8 months).

It was found that self-reported previous team work experience had little bearing on current satisfaction for either cohort. This finding contradicted the conclusions of Drury, Kay, and Losberg (2003) and Wong, Shi, and Wilson (2004). However, the former reported results from a smaller cohort of older students and the latter measured group performance as an indicator of satisfaction which may account for the differences. For the DB1 students there was no correlation between

Material published as part of this journal, either on-line or in print, is copyrighted by the publisher of the Journal of Information Technology Education. Permission to make digital or paper copy of part or all of these works for personal or classroom use is granted without fee provided that the copies are not made or distributed for profit or commercial advantage AND that copies 1) bear this notice in full and 2) give the full citation on the first page. It is permissible to abstract these works so long as credit is given. To copy in all other cases or to republish or to post on a server or to redistribute to lists requires specific permission and payment of a fee. Contact Editor@JITE.org to request redistribution permission. perceived usefulness of the team work training and the satisfaction. However, there was a small significant correlation for the SEP students. This result may have been due to the nature of the training offered. The training for the DB1 students was of a passive self directed nature whereas the SEP students were offered a two-day workshop. There was no support for the hypothesis that working with friends 
would influence satisfaction. However, this finding is difficult to interpret given the way in which we assessed previous familiarity with team members. Finally, it was found that working in mixed gender teams was more satisfying for students working on long ( 8 month) projects than for students working on short duration ( 5 week) tasks, supporting previous work by Wong et al. It was proposed that the longer term project allowed the team to become better acquainted and better able to capitalize on the communication skills of females. This proposal will require further research.

Keywords: Satisfaction, group, team, project, duration, gender, friends, experience, education, university.

\section{Introduction}

Employees in most jobs will be required to work as part of a team (DEST, 2002), and experience in a team is usually an important criterion in the selection process carried out by employment agencies or human resource departments.

Often a key question asked of the candidate is whether they have played team sports, or been in committees, or been in the debating team. What the interviewer is trying to find out is not (a) sporting prowess; (b) political savvy, or (c) public speaking skills (although these are usually important). The point is to see if the candidate can work effectively within a group of peers.

Modern university courses attempt to foster team skills, usually by setting team assignments or projects. Training in interpersonal relationships is minimal and the assumption is that if a student has sufficient experience in working within a team, they will be good at working in a team. The effectiveness of this strategy is rarely measured.

Recently it has been demonstrated that many students do not want to work in teams, and actively resent being forced to work with each other (Drury, Kay \& Losberg, 2003; Waite \& Leonardi, 2004). Sometimes team-based assignments have been set for tasks which would not normally be done by teams, possibly to reduce the marking burden for the academics. This behavior by the academics has been interpreted cynically by the students, who may be less than willing to undertake team-based assessment for tasks where team work is appropriate (Waite \& Leonardi, 2004).

This work attempted to determine the extent of satisfaction of students with their team work experiences in two Information Technology (IT) subjects, and to determine some of the factors which may be used as predictors of satisfaction with team work.

\section{Literature Review}

Previous research has identified a number of factors that are thought to impact on student satisfaction with team work. In particular, the duration of the project and the composition of the team appear to be important. While some aspects of these issues will be addressed in this paper, our main goal is to determine the factors influencing team work satisfaction within self-selected teams. To achieve this goal, the authors had to identify an instrument for measuring team work satisfaction, and in consequence - effectiveness (Hacker, 1997).

The terminology used in the literature when referring to people working together on a common goal is inconsistent. Many authors use the term teams, while others use the term groups. We have chosen to define a team as group of people who are

- working towards a common goal;

- cohesive-i.e. knowledgeable of each other and each other's abilities and tasks;

- cooperating to obtain a common goal; 
- sharing resources.

This definition serves well for describing student teams bound by a common assessable task.

We define groups as collections of people with common attributes (e.g. cohorts of students) but no common goal requiring cooperation.

Where authors have referred to research on groups, but where the situation of the 'group' is consistent with our definition of 'team', we interpret the term 'group' to mean 'team' in our context.

\section{Ways of Measuring the Effectiveness of Team Work}

A brief review of the literature reveals different ways of measuring the effectiveness of team work.

Performance measures may take the form of a summative assessment which involves comparing a team's design with a model solution (Porter \& Lilly, 1996; Sargent \& Sue-Chan, 2001).

While many researchers have associated the measurement of team performance with the quality of a product or the achievement of some goal, other researchers have considered the sociopsychological aspects such as using "Member Satisfaction" as a measure of 'Group Performance' (Hacker, 1997).

Satisfaction measures involve asking questions about the team process from the team participants themselves. The team members answer such questions by reflecting on their team work and reporting their subjective assessment of it. This could take the form of efficacy (Sargent \& SueChan, 2001) - a team's shared belief in their ability to complete a specific task; group potency (Sargent \& Sue-Chan, 2001) - a team's shared belief in their own ability; satisfaction (Keyton, 1991) - a measure of how 'happy' students are while doing team work or 'decision process satisfaction' (Wong, Shi \& Wilson, 2004) - contentment of team members with their decision making process.

It can be argued that the pedagogical objective of student team work should not be the team performance as judged by the marks attained for project work. The objective should be to improve the learning of each individual that participates in the team work. Collaboration is considered by educationalists to improve students' learning. It has been shown that a correlation exists between satisfaction with group work and a willingness to undertake group work (Martinez, Cheng, Smith, Smith \& Yoon, 2002). If research can lead to a better understanding about the nature of individual student satisfaction with team work, educators may be able to apply that knowledge in the form of interventions that will lead to students who are both better satisfied with team work and have improved learning experiences.

There is some debate whether subjective satisfaction assessments can be used to predict team work outcomes like performance or productivity. Wong, Shi, and Wilson (2004) found that in teams lasting hours, decision process satisfaction was not a significant predictor of team performance. Ocker (2002) obtained results which suggested that satisfied, "cohesive" teams performed better and Lovell and Nunnery (2004) suggested that "group member satisfaction" was almost as important to a team's output as team performance.

Instruments for measuring the satisfaction of students with their team work have been developed by Keyton (1991) and Drury, Kay, and Losberg (2003). Drury's survey statements measure general satisfaction with team work. Keyton's research indicated that there were two dimensions to measuring satisfaction in team work: global and situational. Global satisfaction referred to a generic opinion about how the team was functioning and situational satisfaction to factors specific to the particular project. Her work indicated that negative (dissatisfaction) statements could be reverse-scored for global questions, but not for situational statements. 


\section{Factors Which Influence Team Work}

Various factors have been identified which may be important in determining team work outcomes. Factors identified include the duration of the team work, an individual's previous experience with team work, their perception of team work training materials, the degree to which they had worked with their team members before, and whether they were working in a team that had a mix of both males and females. These are now discussed in further detail.

\section{The influence of team duration}

Opinion in the literature is divided over the relationships between task duration, team duration, team satisfaction and performance.

Druskat and Kayes (2000) investigated the effect of various team processes on student team learning and performance. They surveyed post-graduate students involved in 15-week projects (after 10 weeks) and found that team learning (sharing unique knowledge) and team performance (grade) did not correlate. This finding conflicted with previous work by Edmonson (1999) who found that there was a correlation between learning and performance in teams. The duration of the team projects in Edmonson's study was longer than those in Druskat and Kaye's study. Druskat and Kayes concluded that team duration had a significant effect on the effectiveness of particular team processes. They suggested that processes within the team should be tailored to the team (and/or task) duration.

Bradley, White and Mennecke (2003) reviewed the literature on task-specific and ongoing teams working on both very short-term (1-6 hours) and long-term (3-6 month) tasks. They concluded that the time scale of the task had a significant influence on the effectiveness of team intervention strategies. When doing very short-term tasks (50 to 120 minutes), team members were taskfocussed and attempts to promote interpersonal relationships within the team were ineffective in improving team work outcomes such as satisfaction and output. For longer term projects (4 to 15 weeks), such forms of intervention were useful, particularly if the team was ongoing and working on a sequence of short or longer-term tasks.

From these findings it could be expected that on-going teams working on long-term tasks may become more satisfied (and maybe more productive) than transient teams working on short tasks.

\section{Previous experience with team work}

The literature indicates that experience with team work may have a beneficial effect on satisfaction with a team and its processes.

Experience with teamwork appeared to be an important factor in a team's success (Wong, Shi, \& Wilson, 2004). Their work concentrated on task-relevant experience within the team. They concluded that team work experience influenced team work satisfaction. In addition, recent work at Sydney University with computing students by Drury, Kay and Losberg (2003) found that $3^{\text {rd. }}$ year project students had improved interpersonal and self-evaluation skills compared to first-year students, and this had influenced their attitude to group [sic] work.

Drury, Kay and Losberg (2003) also found that the amount of experience a student had with team work had a strong effect on the student's satisfaction with the team work experience. The firstyear students were put into small teams (4 students) for short-term (4 week) projects. In contrast, third-year students were put into large (10-student) teams to work on longer-term projects (approx. 15 weeks) and were far more satisfied with their team experience. Factors such as student age, technical knowledge, and the nature and duration of the project task may have influenced this result. 


\section{Intervention strategies}

For short term teams composed of 'naïve' students some sort of intervention could be used to improve the team experience.

Bradley, White and Mennecke (2003) found that the effectiveness of intervention strategies depended on the type of intervention and the time-scale of the team and/or task. Training in interpersonal skills improved team performance in both ongoing teams working on short-term tasks and short-term teams working on short-term tasks (hours). However, they were unable to determine the effect of intervention on short-term (hours) teams working on ongoing tasks. An increase in team performance may have translated to an improvement in team work satisfaction.

\section{Team composition}

Various researchers have investigated possible predictors of team work satisfaction and other outcomes. One area for research has been to manipulate the composition of a team to maximise its chances of success (Brown, Kladstorin, \& Valluzzi, 1990; Cooper, Robinson, \& McKinney, 1994; Houldsworth \& Mathews, 2000; Lovell \& Nunnery, 2004). Subject coordinators have the opportunity to "design" teams by choosing who goes in which team.

Porter and Lilly (1996) found that in project-based teams, trust played an important role in the mitigation of conflict within the team. By maximising trust, and reducing conflict, teams performed better in tasks which did not require creative input. This finding suggested that teams of like-minded and otherwise similar people performed better than teams composed of people with different backgrounds or attitudes. Lovell and Nunnery (2004) concluded that

"a group of adults aggregated homogeneously according to 'epistemic language' will be more satisfied with the grouping arrangement than a group not so aggregated";

in other words: homogeneity... predicts greater satisfaction.

Some authors argued that homogeneity was bad for team performance. Houldsworth and Mathews (2000) found that teams with a diverse mixture of gender, age and experience performed more consistently.

Wong, Shi, and Wilson (2004) studied $3^{\text {rd. }}$ year university students allocated to teams for a single team-based task. The task was preceded by a training session (on the task - not on team processes), followed by team formation, the task completion and a post-task survey. Task duration was of the order of hours. They showed that having a mix of genders improved "socio-emotional" communication, which in turn led to improved "social presence", leading to "decision process satisfaction", leading to better "group performance"[sic]. Our interpretation of this result is that teams containing both genders contain females, who communicate better, leading to happier and more effective teams. Savicki, Kelly and Ammon (2002) also explored the connection between the communication style of women and team satisfaction and Houldsworth and Mathews (2000) found that mixtures of gender were beneficial.

Team composition is a variable which can be manipulated in an academic environment. It would be useful to determine if satisfied teams have compositions of a particular type, eg. mixed gender or asocial groups (strangers).

\section{Background to Our Study}

Satisfaction is convenient for researchers to measure. Predictor and screening questions can be combined with satisfaction questions in a survey. In addition:

- $\quad$ Research subjects can be surveyed without identifying themselves, which would be necessary if actual outcomes such as productivity or marks (assessment) were used. 
- $\quad$ Because no assessment of the task outcomes is needed, the surveys can be administered during the course of a team-based task, when students are easy to assemble in one place.

- This approach lends itself to project work where the projects are all different because the measure is of attitude not performance. There is no requirement for a standard solution or benchmark.

To extract the most reliable and precise results, researchers usually combine positive statements (where agreement with the statement is interpreted as satisfaction) with negative statements (where disagreement is interpreted as satisfaction). Negative responses are reverse-scored and added to the positive responses, and treated as a single measure of satisfaction.

In the current research we were interested in using a survey tool that could be applied without amendment to a range of subject-specific team work situations. To measure team work satisfaction we chose to use Keyton's proposed set of 24 global satisfier and 14 dissatisfier statements, rather than situational specific statements. Due to the global nature of the statements, it should be possible to reverse-score the dissatisfaction questions to produce a single measure of satisfaction.

\section{Hypotheses}

In the current study we were interested whether a student's self-reported experience at working in teams would correlate with their reported level of satisfaction with their team work. Given previous research we expected that:

Hypothesis 1. High self-reported previous experience with team work will be associated with high student satisfaction with current team work.

In our study we planned to compare the satisfaction levels of the more experienced final year Software Engineering Project students (SEP) with their less experienced Database 1 counterparts (DB) in addition to examining the correlation between experience and satisfaction.

Student teams were provided with training on how to effectively manage their team work process. The training consisted of published notes and advice on managing teams. The SEP students were also provided the option of attending team-building workshops. It was not possible to objectively measure the degree to which individual students made use of this information and their response on the satisfaction survey. Thus, we examined how much the degree to which they perceived the training as useful had influenced their perception of satisfaction with team work rather than their actual participation in training.

Hypothesis 2. Students who perceived the team work training as useful will be more satisfied with their team-work than those who did not.

We examined the degree to which the students had worked with their team members before. It is reasonable to assume that when given a free choice students will choose to work with people they know, trust and are similar to. Porter and Lily (1996) found that trust within a team enhances task productivity. Lovell and Nunnery (2004) found that homogeneous teams are more satisfied with their team experience. These conclusions suggest that self-selecting teams will be more productive and satisfied than randomly formed teams.

Two team formation strategies often used at our institution are: self-selection and pseudo-random. In 'self selection' students form teams with their friends, with students they think capable or with other students who have not managed to be chosen for a team. This leads to three kinds of teams:

- teams where students know each other, either by past association or by reputation;

- teams where students work with strangers;

- a mixture of the above. 
Hamlyn-Harris, Hurst, von Baggo, \& Bayley

Some subject coordinators allocate students to teams in a random or pseudo-random manner. Teams often end up containing cliques of friends as well as outsiders. Often a range of technical abilities, backgrounds and levels of experience with teamwork are represented within the team.

In both subject cohorts, students were allowed to self-select their teams. All three types of teams were present in our study.

Hypothesis 3. Students who report working with people they have worked with before will be more satisfied with their team work than those who do not.

We also examined the relationship between individuals' satisfaction and whether or not they worked in a mixed or single gender team.

Hypothesis 4. Participating in a team where both genders are represented will increase a student's satisfaction with team work compared with those working in single gender teams.

Other factors affecting student perceptions of the team that we have not addressed in this research include task design, assessment, motivation and technical knowledge (Drury, Kay, \& Losberg 2003).

\section{Participants}

In this paper the results of two survey cohorts are described. The first cohort involved small teams working on small short-term projects (2-5 weeks of interaction). The second cohort involved large teams working on a long-term ( 8 month) project (only half completed at the time of writing). Both cohorts were administered a survey that contained a set of questions related to the variables of interest from our hypotheses and a set of questions designed to measure their satisfaction with their recent team work experience.

The first cohort consisted of 270 Database 1 (DB) students working in teams of 3-4 students. Of the 270 students, 236 were undergraduates and 34 were postgraduates.

Participation rates in the survey were $54 \%$ and $34 \%$ for the under- and post -graduates respectively. Participation was determined by the number of students attending the lectures when the survey was administered. Of the 130 students actually participating in the survey (undergraduates and post-graduates combined), 4 completed less than $90 \%$ of the survey. Data from these students was excluded from all analysis giving a total of 126 respondents. Further analysis showed that 4 students who responded to the survey did not participate in a team for their assignment. These students were also excluded. Thus, the analysis reported in the results is based on responses from 122 students.

The Database students came from several courses ranging from multimedia and business to computer science and software engineering, both at under-graduate and post-graduate level. The students were completing the second semester of a 6-semester (under-graduate) or 4-semester (postgraduate) course. Database and other technical subjects in the post-and under-graduate courses are identical, but the number of foundation and generic-skill subjects in the under-graduate course is greater.

The second cohort of participants consisted of 100 Software Engineering Project (SEP) students working in teams of 5-8 students. The response rate (70\%) was determined by the number of students attending the lecture when the survey was administered. Of the 70 respondents, 3 completed less than $90 \%$ of the survey. Data from these students was excluded from all analysis giving a total of 67 respondents. All students who responded to the survey participated in a team for their project. The analysis reported in the results is based on responses from 67 students.

The SEP students were in the final year of a 3-year computer science and software engineering under-graduate degree or a 5 year double degree. 


\section{Duration}

A key distinction in previous research on the effect of team duration on team processes was whether the project was a "short term" or "long term" project. In the literature no consistent definitions of the durations of short- and long-term tasks were evident. Some authors referred to tasks taking 40 minutes as short-term tasks, while others considered a 6-month project to be a shortterm task. The authors of this work will describe the duration of team-based tasks by their actual duration (where known) or by an estimate of the order of the duration.

We chose to investigate two cohorts of students doing tasks of different durations to see if task duration was a mitigating factor in our investigation. For each cohort we planned to evaluate each of the four hypotheses to determine task duration effects.

The DB cohort was engaged in a 2-5 week task (the third and final assignment for the subject). Teams were encouraged to form up to two weeks before the assignment was set.

The SEP cohort was engaged in widely varying final year projects, lasting 8 months. Teams were formed about one week before the projects started. Our evaluation of team work satisfaction took place after 5 months.

\section{Materials}

The survey consisted of two parts. Part 1 contained questions related to screening of students and variables that may affect team work satisfaction (see Table 1). The initial question confirmed that they had worked in a team for the assignment. Statement 1 related to their previous experience with team work. Statement 2 attempted to gauge the level of usefulness of written information and/or workshop activities about team work which had been made available to them. Statement 3 related to the degree to which they had worked with team members before and Statement 4 related to whether their team was of single or mixed gender composition. Students were asked to respond "yes" or "no" to Statements 0 and 4. For Statements 1, 2, and 3 students were asked to indicate their level of agreement with the statements on a 5-point scale with a range from Strongly Agree (5) to Strongly Disagree (1).

\begin{tabular}{|c|l|}
\hline \multicolumn{2}{|c|}{$\begin{array}{c}\text { Table 1: Screening and predictor } \\
\text { statements used in Part 1 of the survey. }\end{array}$} \\
\hline No. & Statement \\
\hline 0. & I am working in a group for this subject. \\
\hline $\mathbf{1 .}$ & I have worked in groups on many assignments/projects before. \\
\hline $\mathbf{2 .}$ & $\begin{array}{l}\text { I found the "Teamwork Training Notes" and "Team Leader's Ad- } \\
\text { vice" on Blackboard were useful.* }\end{array}$ \\
\hline 3. & I have worked with members of my team before. \\
\hline 4. & There are both male and female students in my group. \\
\hline
\end{tabular}

*Blackboard is an internet-based content delivery system freely accessible by the students.

Part 2 of the survey contained statements related to the respondent's feelings towards their team work experience. The statements were taken from those suggested by Keyton (1991) and consisted of both Global Satisfaction (e.g., I feel good about our group activity) and Global Dissatisfaction (e.g., Not everyone in the group is participating) statements. There were 24 satisfaction statements and 14 dissatisfaction statements (a full list of the items is provided in the Appendix). Students were asked to indicate their level of agreement with the statements on a 5-point scale with a range from Strongly Agree (5) to Strongly Disagree (1). 
Hamlyn-Harris, Hurst, von Baggo, \& Bayley

The Keyton statements generally used the term 'group' instead of 'team'. The statement wording was not altered so that results could be compared with the results of previous research using the same statements.

The survey was identical for both the DB and SEP cohorts, with one exception. Students from this SEP cohort had received explicit training in team work during a two-day workshop approximately 5 months before the survey. To accommodate this difference the question from study 1 ("I found the Teamwork Training Notes and Team Leader's Advice on Blackboard were useful.") was re-worded to refer to the workshop on teamwork. The support and intervention strategies are described in the procedure section.

Students from the DB cohort were given the opportunity to download the same workshop materials from an on-line content delivery system called 'Blackboard'.

\section{Procedure}

Prior to administration of the survey the DB cohort were encouraged to form teams of between 3 and 4 members with the aim of completing a major assignment. The assignment was the most challenging of the semester and required the design and implementation of a database. Previous individual assignments had only required implementation. Over $90 \%$ of the students enrolled in the subject were involved in a team submission for this assignment.

The students were given 3 weeks to complete the assignment, but were encouraged to form their teams about 2 weeks prior to the setting of the assignment. The maximum amount of time students spent working with their team was approximately 5 weeks. Students were required to register their team with their tutors and to work in their teams on related tutorial questions and design tasks as well as the assignment.

Support material on team formation, dynamics, leadership and procedure was made available to the DB students from the time the students started to form into teams. The material was made available through Blackboard - a web-based content delivery system. The material took the form of documents and slide shows, and was largely based on material used in workshops delivered to the SEP students (see later). Use of the DB support material was voluntary. No attempt was made to track which students had read the material.

After assignment submission (but prior to the return of assignment grades) the students were given the Team Work Satisfaction Survey. The survey was administered during their normal lecture time.

For the SEP cohort, students were required to form teams of at most eight students with the aim of commencing a major software project spanning two semesters. The survey was administered at the first lecture of the second semester of this project. At this point students had been working in their teams for about 5 months.

Intervention for the SEP students took the form of a two-day workshop composed of lectures (team psychology, management, documentation) and a variety of team-based activities (design, construction, presentation, testing). Overall, the workshop lasted for 21 hours.

\section{Results}

\section{Data Analysis and Screening Procedures}

The dissatisfaction statements were reverse-scored and a reliability analysis was performed on the items using SPSS. The data from all respondents who satisfactorily completed the survey was used. This showed the Satisfaction Scale had a Cronbach's alpha (Cronbach, 1990) of 0.9485. 
This alpha was within the acceptable range. The scores for each participant were subsequently averaged to obtain an overall global mean Satisfaction rating for each participant.

Prior to further analysis, the resultant Satisfaction ratings were checked for normality using SPSS Explore. The ratings showed significant departure from normality (kurtosis $=1.041$ and skewness $=-.159$ ). Seven outliers were identified (all low, 5 from DB and 2 from SEP). These were deleted resulting in an acceptable level of kurtosis and skewness (kurtosis $=-.197$ and skewness $=-.198$ ).

Differences in question responses between the DB postgraduate group and the DB undergraduate group were briefly investigated to see if the two groups would produce divergent results. A t-test was used to compare the average responses for each question between post-graduate and undergrad groups. A significant differences were found for only the screening statement relating to the usefulness of team training (post-graduates: $M=3.53, S D=0.72$; under-graduates: $M=2.88$, $S D=1.07)[t=3.19, p>.05]$.

T-tests were also used to check the differences in responses for satisfaction questions, and these are presented in the next section.

\section{Survey Results}

The results of the survey will be reported as they relate to each of the four hypotheses discussed previously.

\section{Hypothesis 1. High self-reported previous experience with team work will be associated with} high student satisfaction with current team work.

To assess the relationship between a students experience with team work and satisfaction we first had to establish that the SEP teams were more experienced than the DB teams (see Table 2). An independent $t$-test confirmed that the SEP students rated themselves as significantly more experienced at working in teams $(M=4.20, S D=0.73)$ than the DB students $(M=3.49, S D=1.19)$ $[t(177.36)=4.951, p<.001]$. Despite this, the SEP students were not more satisfied $(M=3.56$, $S D=0.45)$ than the DB students $(M=3.64, S D=0.45),[t(1180)=1.147, p>.05]$. To investigate whether there was an association not identified by the $t$-test, a Pearson's product-moment correlation was calculated for both DB and SEP students. However, the result also showed that there was no significant correlation between "working in groups on many projects before" and satisfaction for either the DB or SEP students.

A t-test comparing post- and under-graduate students' reported experience with team work showed no significant difference between post- and under-graduate groups (post-graduates: $M=3.00, S D=1.01$; under-graduates: $M=3.31, S D=1.00)$ [ $t=-1.19, p<.05]$.

\section{Table 2: Mean (SD in parentheses) Ratings for Part 1 of the survey for DB and SEP students. Note: 5 = high agreement, $1=$ low agreement with statement}

\begin{tabular}{lccc}
\hline Statement & Subject & N* & Mean (SD) \\
\hline $\begin{array}{l}\text { 1. I have worked in groups on many assignments/ projects } \\
\text { before. }\end{array}$ & DB & 116 & $3.49(1.19)$ \\
\hline $\begin{array}{l}\text { 2. I found the Teamwork Training Notes and Team Leader's } \\
\text { advice on Blackboard were useful. }\end{array}$ & DB & 114 & $2.99(1.04)$ \\
\hline $\begin{array}{l}\text { 3. I have worked with members of my team before. } \\
\text { * Note: Some participants did not respond to some of the statements. }\end{array}$ & DB & 65 & $3.09(1.13)$ \\
\hline
\end{tabular}


Hamlyn-Harris, Hurst, von Baggo, \& Bayley

Hypothesis 2. Students who perceived the team work training as useful will be more satisfied with their team work than those who did not.

The relationship between reported usefulness of the team work training provided and satisfaction was explored using Pearson's product-moment correlation. There was no significant correlation between the rated usefulness of training and satisfaction for the DB students. However, there was a small significant correlation for the SEP students $(r=.249, n=65, p<.05)$. An independent $t$-test showed that although the SEP students received more formal training in team work, they did not report it as any more useful than the DB students $(t<1)$. The mean usefulness of training rating for the DB and SEP students can be seen in Table 2.

Hypothesis 3. Students who report working with people they have worked with before will be more satisfied with their team work than those who do not.

An independent $t$-test showed that the SEP students more strongly agreed with the statement that they were working with people they had worked with before $(M=3.98, S D=1.00)$ than the DB students $(M=2.84, S D=1.41)[t(168.406)=6.286, p<.001]$. However, there was no significant Pearson's product-moment correlation between agreement on the statement and satisfaction for either subject group. Working with friends did not seem to influence overall satisfaction.

Hypothesis 4. Participating in a team where both genders are represented will increase a student's satisfaction with team work compared with those working in single gender teams.

A two-way between groups analysis of variance was conducted to examine the influence of Cohort (DB vs SEP) and gender mix (Single vs Mixed) on satisfaction ratings. A statistically significant interaction was found between Cohort and Gender Mix in satisfaction ratings $[F(1,177)=$ $5.314, p<.05]$

Table 3: Mean Satisfaction (SD in parentheses) Ratings as a function of Cohort and Gender Mix. Note: 5 = high agreement, $1=$ low agreement with statement.

\begin{tabular}{clcc}
\hline Cohort & \multicolumn{1}{c}{ Gender Mix } & N & Mean Sat. (SD) \\
\hline \multirow{2}{*}{ DB } & Single & 79 & $3.67(0.42)$ \\
& Mixed & 37 & $\underline{3.57(0.51)}$ \\
& Difference & & 0.10 \\
\hline \multirow{2}{*}{ SEP } & Single & 43 & $3.47(0.46)$ \\
& Mixed & 22 & $\underline{3.72(0.41)}$ \\
& Difference & & 0.25 \\
\hline
\end{tabular}

The size of the effect was small (partial eta squared $=.03$ ). There were no significant main effects of cohort or gender mix on satisfaction. Table 3 shows that that the SEP students were more satisfied if they were in a mixed team than in a single gender team. In contrast there is no difference between the single gender and mixed teams in the DB subject.

Comparisons of the responses of post-graduates (DB) compared to undergraduates (DB and SEP) showed little difference in terms of satisfaction measures. Of the 38 satisfaction/dissatisfaction questions, only two - relating to team meetings - were answered differently by the different groups. The questions were: Everyone attends each group meeting (post-graduates: $M=3.76$, $S D=1.25$; under-graduates: $M=3.16, S D=1.27$ ) [ $t=1.83, p>.05]$; and Our group spends its time well (post-graduates: $M=3.94, S D=0.66$; under-graduates: $M=3.44, S D=1.04$ ) [ $t=2.66, p>.05]$. 


\section{Discussion}

The results of the study will be discussed in relation to each of the hypotheses.

\section{Previous Experience with Team Work}

This study showed that the self-perceived previous experience of a student in team work had no significant effect on the degree of satisfaction of the student with their current team work. This result undermined the assertion of many academics that students who do a lot of team work will "get good" at doing team work.

This result contradicts the findings of Drury, Kay and Losberg (2003), who concluded that "...by third year, students have adapted well to working in groups as opposed to ... first years."

Drury's sample size for the older students was small (36) and no rigorous statistical testing was done to prove Drury's conclusion.

This result also contradicts a study by Wong, Shi and Wilson (2004), who found that "... experience ... gained in the same organizational environment have [sic] a positive effect on group performance".

Wong qualifies this result by suggesting that the group performance measurement was not sufficiently objective. The students being assessed performed better because they had the experience to know what the assessor wanted - not because they were more experienced in team work or task management.

It appears that setting team-based tasks is not necessarily a way of developing a student's satisfaction with team work.

\section{Perceived Usefulness of Training}

The hypothesis that training in teamwork that is perceived as being useful will lead to greater satisfaction was not supported for the DB students. This result is not surprising considering that the form of training was voluntary and passive (reading documents / slides). It appears that this form of training was not considered of value (and may not have been effective). Students, particularly first year students seem to prefer an active presentation of material (e.g. lectures, labs, workshops). Providing passive support material may have been effective for the older post-graduate students, but this could not be proven statistically.

The hypothesis that training in team work that is perceived as being useful will lead to greater satisfaction was supported for the SEP students, although the correlation was quite small. These students received a 2-day workshop consisting of lectures and activities.

The results generally suggested that effectiveness of intervention or support strategies which attempted to engender team work skills was not dependent on the attitude of the student to the intervention. While team work training may have had a positive effect on team skills, the student's perception of its value was not a factor that appeared to be related to team work satisfaction.

This result supports the findings of Bradley, White and Mennecke (2003). Active intervention, particularly when it is task based (such as workshops on team skills and team-based tasks) can be effective in increasing team satisfaction with team performance. 


\section{Working with Previous Team Members}

Working with people that they had worked with before did not significantly influence overall satisfaction with team work. This may not have been surprising for the DB students, most of whom were only in first year and may have had limited opportunity to have formed previous relationships. However most of the SEP students had had a great deal of experience with team work and significant opportunity to work with people they had worked with before. Given that their teams were self-selected it was expected that they would have chosen and been more satisfied with people with whom they had had previous experiences. Porter and Lily (1996)'s work suggests that teams composed of people who trust each other will perform better on task-based projects. Our findings could not confirm this conclusion because we did not measure team performance. Lovell and Nunnery (2004) concluded that homogenous teams are more satisfied. Our work did not support this conclusion. The SEP students were not more satisfied if they were in teams composed of people they knew. On reflection, perhaps the important information students gained from working with other students in the past was not necessarily with whom to work again, but rather with whom they should not work again.

\section{Gender Mix}

Having both genders represented in short term (i.e., less than 5 weeks) assignment teams was shown to have no influence on student satisfaction with team work. However, longer term (8 month) project teams showed that the mixing of genders within the team had a small beneficial effect on satisfaction.

This result partially confirmed the finding of Wong, Shi, and Wilson (2004). Wong studied 'workshop' tasks where participants received training in a task, formed teams, performed the task, and completed a diagnostic survey about their attitudes all in one day. Participants were effectively forced to interact with each other without respite in a 'hot-house' environment. Wong found that females facilitated communication and increased "social presence", leading to a higher level of satisfaction with team decisions and team performance. However, Wong's work involved short duration tasks (of the order of hours). In our study the short term task was in the order of weeks and the work performed by the DB students was less intense. Students were free to meet with their team whenever they liked with a minimum interaction of 2 hours per week (class time). Tasks could be assigned to individuals and performed in parallel. Collaboration was only required for the design part of the assignment, which may have only lasted hours. It is possible that the tasks were so fragmented that interpersonal communication may not have been as important to task completion as in the more intense task studies by Wong.

In contrast, the results of the present study suggested a small benefit to having both genders in teams which collaborate over a much longer period of time (5 months). The SEP students were working on a longer project (with a total expected length of 8 months). Although the time line was much longer, and opportunities for task avoidance were greater, there was also more time for the development of social units within the team. As time progressed, students would get to know each other and discover each other's skills. Such a process of discovery would allow team members to capitalise on the communication abilities of females in the team, leading to a more efficient and productive team. If this interpretation of the results is correct, future work following up on the SEP teams would show increased satisfaction in teams where females are present. This will be a topic of future research.

The main limitation with this study is the efficacy of the statements we used to measure the variables of interest. For example, it may have been difficult for students to quantify on a 5 point agreement scale the degree to which they had previously worked with other team members. More 
sophisticated and detailed questions about previous relationships within their team may have revealed better correlations with satisfaction.

There may also be some concern about the validity of the satisfaction survey we used. Future work may involve attempting to further validate the results of the survey with other measures of satisfaction such as qualitative interviews with specific groups of individuals.

\section{Conclusions}

The results of this study indicated that satisfaction with team work was not easily predicted using the parameters investigated in this work. Students who have had experience in team based tasks before, who found teamwork training useful, and who worked with people they have worked with before did not necessarily consider themselves to be more satisfied with team work.

A very slight increase in satisfaction in teams containing both males and females was detected in longer term ( 5 month) teams, and it is proposed that this effect may grow with time as students discover how to make use of the different abilities of members of the team. Future work will follow up on the longer term teams ( 5 months) to see if the proposed effect is detectable.

\section{References}

Bradley, J., White, B.J., \& Mennecke, B.E. (2003). Teams and tasks: A temporal framework for the effects of interpersonal interventions on team performance. Small Group Research, 34(3), 358-387.

Brown, K.A., Kladstorin, T.D., \& Valluzzi J.L. (1990). Project performance and the liability of group harmony. IEEE Transactions on Engineering Management, 37(2), 117-125.

Cooper, J. L., Robinson, P., \& McKinney, M. (1994). Cooperative learning in the classroom. In Diane Halpern (Ed.), Changing college classrooms: New teaching and learning strategies for an increasingly complex world (pp. 74-92). San Francisco, USA: Jossey-Bass.

Cronbach, L. J. (1990). Essentials of psychological testing (5th ed.). New York, USA: HarperCollins.

DEST (2002). Employability skills for the future. Department of Education, Science and Training, Commonwealth of Australia. Retrieved August 10, 2005, from http://www.dest.gov.au/sectors/training_skills/publications_resources/profiles/employability_skills_for the future.htm

Drury, H., Kay, J., \& Losberg, W. (2003). Student satisfaction with groupwork in undergraduate computer science: Do things get better? Australasian Computing Education Conference (ACE2003), Adelaide. Australia. Conferences in Research and Practice in Information Technology, 20, 77-85.

Druskat, V.U., \& Kayes, D.C. (2000). Learning versus performance in short-term teams. Small Group Research, 31(3), 328-353.

Edmonson, A. (1999). Psychological safety and learning behavior in work teams. Administrative Science Quarterly, 44(2), 350-383.

Hacker, M.E. (1997). The effect of decision aids on work group performance. Ph.D. Dissertation , Virginia Polytechnic and State University. Retrieved August 10, 2005, from http://scholar.lib.vt.edu/theses/available/etd-73092339731121/unrestricted/etd.pdf

Houldsworth, C., \& Mathews, B.P. (2000). Group composition, performance and educational attainment. Education \& Training, 42(1), 40-53.

Keyton, J. (1991). Evaluating individual group member satisfaction as a situational variable. Small Group Research, 22(2), 200-219.

Lovell, W., \& Nunnery J. (2004). Testing the adult development of Babel hypothesis: Homogeneous by Perry position collaborative learning groups and graduate student satisfaction. Journal of Adult Development, 11(2), 139-150. 
Martinez, R., Cheng, A. S., Smith, K., Smith, M., \& Yoon, S. (2002). Indiana University Instructional Systems Technology (IST) graduate student attitudes towards group work. Y520: Strategies for educational inquiry Section 5982, Fall 2002 Group Project Reports. Retrieved August 18, 2005, from http://www.indiana.edu/ educy520/sec5982/week_15/rmacksmssy.pdf

Ocker, R.J., (2002): The mediating effect of group development on satisfaction in a virtual and mixedmode environment. Proceedings of the $35^{\text {th }}$ Annual International Conference in Systems Sciences (HICSS'02) 1, IEEE Computer Society. Retrieved August 16, 2005, from http://csdl2.computer.org/comp/proceedings/hicss/2002/1435/01/14350015b.pdf

Porter, T.W., \& Lilly, B.S. (1996). The effects of conflict, trust and task commitment on project team performance. The International Journal of Conflict Management, 7(4), 361-376.

Sargent, L., \& Sue-Chan, C. (2001). Does diversity affect group efficacy? The intervening role of cohesion and task interdependence. Small Group Research, 32(4), 426-450.

Savicki, V., Kelly, M., \& Ammon, B. (2002). Effects of training on computer-mediated communication in single or mixed gender small task groups. Computers in Human Behaviour, 18, 257-269.

Waite, W.M. \& Leonardi, P.M. (2004). Student culture vs group work in computer science. SIGCSE'04, March 3-7, 2004, Norfolk, Virginia, USA, 12-16.

Wong, Y.K., Shi, Y., \& Wilson, D. (2004). Experience, gender composition, social presence, decision process satisfaction and group performance, ACM International Conference Proceeding Series, 58, 110.

\section{Appendix}

\section{Global Satisfaction Scale Items}

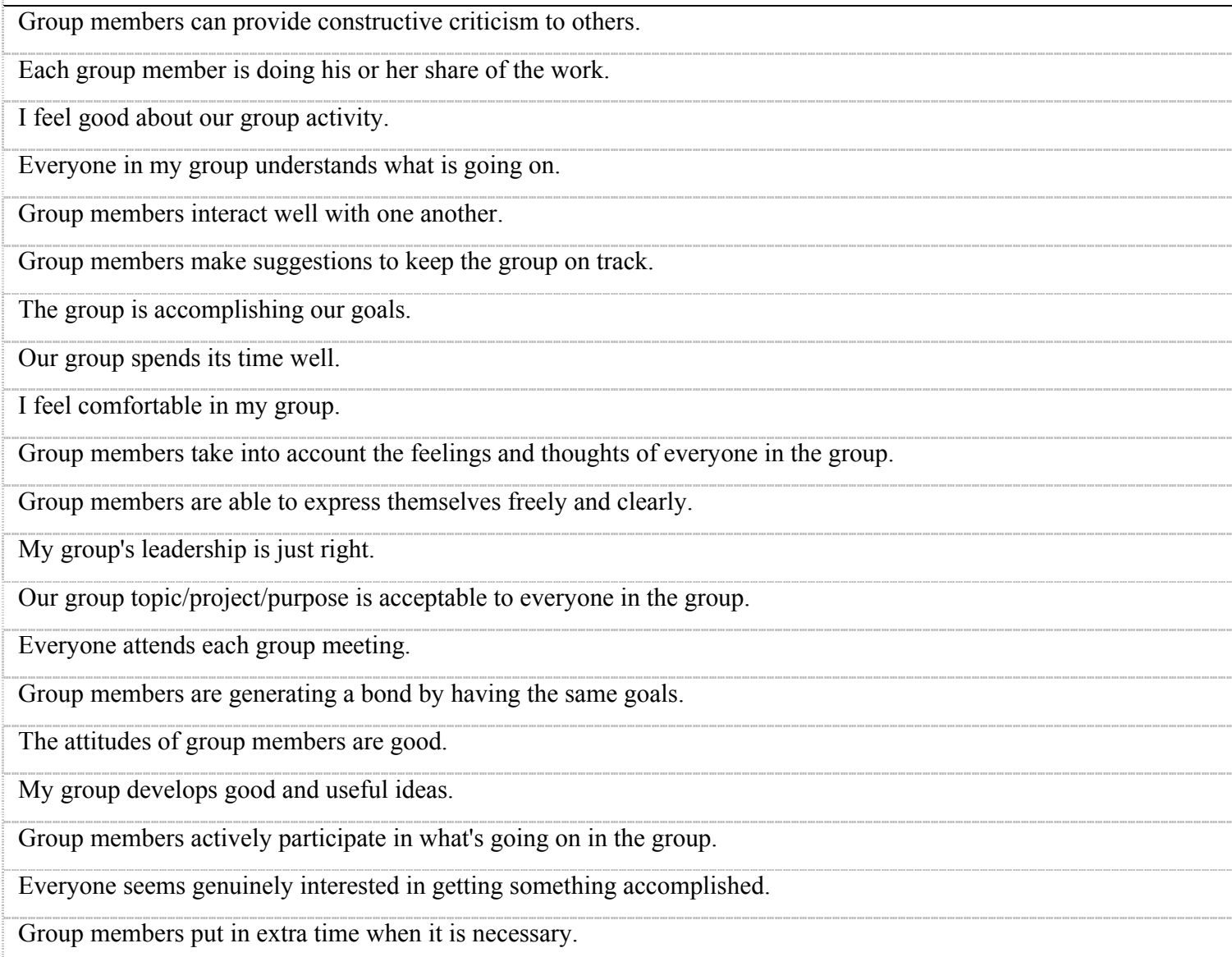


As a group, we like one another.

My group has a good time; we can laugh and joke at our mistakes.

Group members do the tasks that they are supposed to do.

My group members are hard workers.

Our group spends its time well.

\section{Global Dissatisfaction Scale Items}

Some of my group members are closed-minded to others' suggestions.

Group members spend too much time playing around or goofing off.

It is difficult to send and receive messages in the group.

My group isn't very efficient.

My group lacks organization.

My group members have little patience.

Not everyone in the group is participating.

The individual effort given by group members is not adding up to the total group effort needed to accomplish our goals.

It is difficult for my group to come to a decision.

In group discussions, individual contributions are somehow lost in the shuffle.

In group discussions, group members often interrupt one another.

I am confused about exactly what direction the group is going.

It's frustrating when my group works but gets little done.

My group gets sidetracked by distractions.

\section{Biographies}

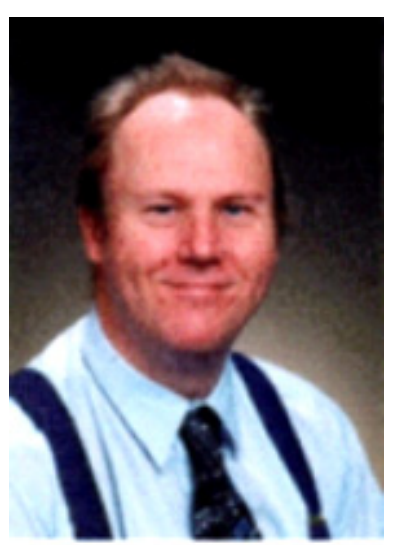

James Hamlyn-Harris is a lecturer of $\mathrm{C}$ and $\mathrm{C}++$ and final year projects at Swinburne University of Technology's Faculty of Information and Communication Technologies. He holds a Ph.D. in Engineering from the University of Queensland and a Masters of Applied Science from RMIT University.

His research interests include generic skills and IT education, signal processing, games programming and software modeling. 

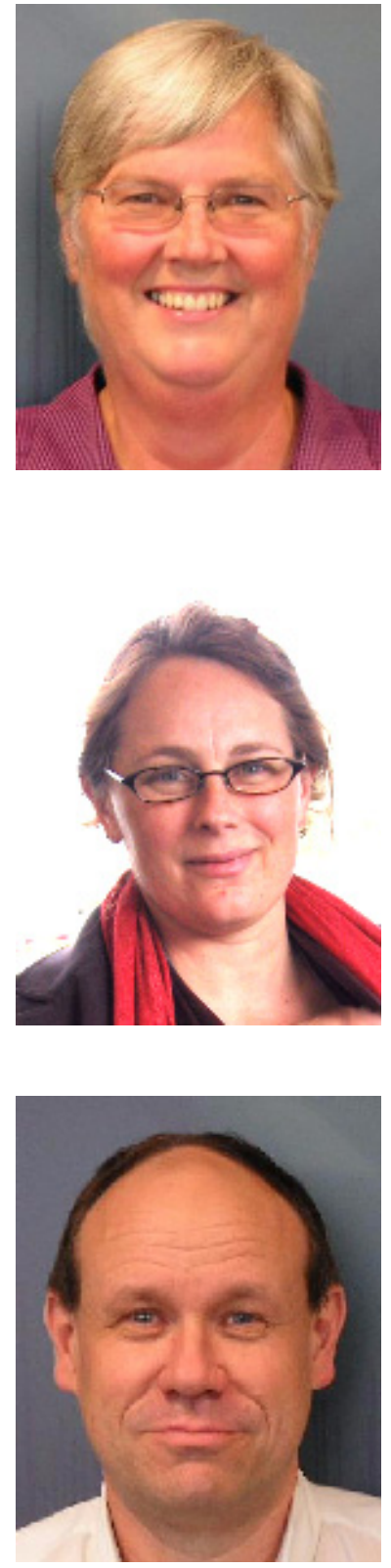

Barbara J. Hurst is the Director of Software Engineering Programs and a lecturer of software engineering, software modeling and final year projects at Swinburne University of Technology's Faculty of Information and Communication Technologies. She holds a Masters of Information Technology and a Bachelor of Science.

Her research interests include team work and declarative languages.

Karola von Baggo is a lecturer of human computer interaction and usability at Swinburne University of Technology's Faculty of Information and Communication Technologies. She holds a Ph.D. in Psychology and a Bachelor of Science (hons), both from Monash University. Her research interests include team work, usability and mobile devices.

Anthony "Buzz" Bayley is an associate lecturer with Swinburne University of Technology's Faculty of Information and Communication Technologies. During the last five years Anthony has lectured in software engineering and object oriented programming to large cohorts of undergraduate and postgraduate students. Anthony has also been involved with flexible delivery of Software Engineering using Internet Technologies and has managed the help desk and sessional teaching staff for beginning programming subjects. He holds a Master of Information Technology, a Bachelor of Applied Science (Computing) and has completed a Graduate Certificate in Teaching and Learning in Higher Education. His research interests include pair programming and team work. 